\title{
Incidence of the 22q11.2 deletion in a large cohort of miscarriage samples
}

\author{
Melissa K. Maisenbacher , Katrina Merrion, Barbara Pettersen, Michael Young, Kiyoung Paik, Sushma lyengar, \\ Stephanie Kareht, Styrmir Sigurjonsson, Zachary P. Demko and Kimberly A. Martin
}

\begin{abstract}
Background: The 22q11.2 deletion syndrome is the most common microdeletion syndrome in livebirths, but data regarding its incidence in other populations is limited and also include ascertainment bias. This study was designed to determine the incidence of the 22q11.2 deletion in miscarriage samples sent for clinical molecular cytogenetic testing.

Results: Twenty-six thousand one hundred one fresh product of conception (POC) samples were sent to a CLIAcertified, CAP-accredited laboratory from April 2010--May 2016 for molecular cytogenetic miscarriage testing using a single-nucleotide polymorphism (SNP)-based microarray platform. A retrospective review determined the incidence of the 22q11.2 deletion in this sample set. Fetal results were obtained in 22,451 (86\%) cases, of which, 15 (0.07\%) had a microdeletion in the 22q11.2 region (incidence, 1/1497). Of those, 12 (80\%) cases were found in samples that were normal at the resolution of traditional karyotyping (i.e., had no chromosome abnormalities above $10 \mathrm{Mb}$ in size) and three (20\%) cases had additional findings (Trisomy 15, Trisomy 16, XXY). Ten (67\%) cases with a 22q11.2 deletion had the common $\sim 3 \mathrm{Mb}$ deletion; the remaining 5 cases had deletions ranging in size from 0.65 to $1.5 \mathrm{Mb}$. A majority (12/ 15) of cases had a deletion on the maternally inherited chromosome. No significant relationship between maternal age and presence of a fetal 22q11.2 deletion was observed.
\end{abstract}

Conclusions: The observed incidence of 1/1497 for the 22q11.2 deletion in miscarriage samples is higher than the reported general population prevalence (1/4000-1/6000). Further research is needed to determine whether the 22q11. 2 deletion is a causal factor for miscarriage.

Keywords: 22q11.2 deletion, Products of conception, Miscarriage, Single nucleotide polymorphism (SNP) microarray, Bioinformatics

\section{Background}

The 22q11.2 deletion is the most common microdeletion in humans, and is responsible for causing the distinct range of features associated with the 22q11.2 deletion syndrome, which can include congenital heart defects, hypocalcemic hypoparathyroidism, T-cell mediated immune deficiency, palate abnormalities, and intellectual disability [1,2]. The vast majority of 22q11.2 deletions are de novo and are caused by meiotic nonallelic homologous recombination events between low-copy repeats [3]. Although the majority $(\sim 90 \%)$ of patients share a common $2.0-3.5 \mathrm{Mb}$ deletion, approximately $7 \%$ of patients have a smaller $1.5 \mathrm{Mb}$ deletion nested within

\footnotetext{
* Correspondence: mmaisenbacher@natera.com

Natera, Inc., 201 Industrial Road, San Carlos 94070, CA, USA
}

the common deleted region, and $\sim 3 \%$ have rarer atypical deletions occurring outside this region $[1,3]$.

Population-wide estimates of the frequency of the 22q11.2 deletion have ranged from $1 / 4000$ to $1 / 6000[4,5]$, although, because none of these studies were prospective, they are subject to both under-ascertainment and referral biases. True population prevalence is therefore believed to be higher [1]. Recent studies performed in prenatal cohorts have indicated a higher prenatal incidence of $\geq 1 / 1000$ for the 22q11.2 deletion [6-8]. However, given that these studies were retrospective and involved a substantial percentage of cases referred for invasive diagnostic procedures (e.g., due to ultrasound anomalies), these studies are also subject to ascertainment bias. In the absence of a newborn screening program for the detection of 22q11.2 deletion syndrome, true incidence of the deletion remains unknown. 
Recognizing the wide difference between prenatal and postnatal estimates of prevalence, we sought to determine the frequency of the 22q11.2 deletion in a large cohort of miscarriage samples using a singlenucleotide polymorphism (SNP)-based genotyping microarray. In addition to identifying aneuploidies, the SNP array-based method can detect subchromosomal imbalances such as the 22q11.2 deletion at a much higher resolution than traditional karyotyping $(>0.5 \mathrm{Mb}$ vs. $>10 \mathrm{Mb}$ ) [9-11]. Although chromosomal microarray (CMA)-based approaches have already become routine in the pediatric setting and are increasingly being used for the testing of prenatal and adult samples $[8,12,13]$, the use of CMA as a first-line test for the analysis of products of conception (POC) specimens is a relatively new application of this technology $[9,14,15]$.

\section{Results}

Of 26,101 total POC specimens tested, fetal results were obtained for 22,451 (86\%) cases. The remaining 3650 (14\%) cases were excluded from the analysis due to having maternal cell contamination (MCC) $(n=3549$, $13.6 \%)$ or incomplete results $(n=101,0.4 \%$; Fig. 1$)$. A 22 q11.2 deletion was detected in $15(0.07 \%)$ of the 22,451 cases with fetal results, yielding an overall incidence of $1 / 1497$. Two of the 15 cases with deletions were present in a pair of twins; as the twins were dizygotic, we considered the two cases as separate events.

Fifty-eight percent $(13,053 / 22,451)$ of the POC specimens with fetal results were considered abnormal (i.e., had chromosome abnormalities detectable by traditional karyotyping, >10 Mb; Fig. 1). Of these, a 22q11.2 deletion was identified in three cases (incidence, 1/4351),

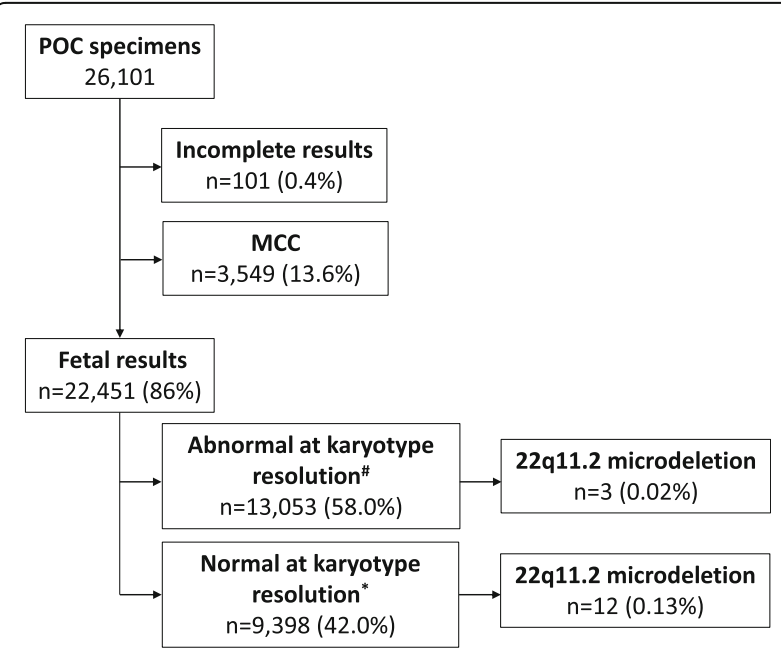

Fig. 1 Summary of the study cohort. "Had chromosome abnormalities that could be detected at the resolution of traditional karyotyping ( $\geq 10 \mathrm{Mb}$ ). ${ }^{*} \mathrm{Had}$ no apparent chromosome abnormalities that could be detected at the resolution of traditional karyotyping one with a typical $3.5 \mathrm{Mb}$ deletion and a finding of Klinefelter syndrome $(47, \mathrm{XXY})$, one with a nested $1.5 \mathrm{Mb}$ deletion and a finding of trisomy 15 , and the third with a rarer $0.65 \mathrm{Mb}$ deletion and a finding of trisomy 16 (Table 1). Among the 42\% (9398/22,451) normal cases (i.e., no chromosome abnormalities detectable by traditional karyotyping), a 22q11.2 deletion was identified in 12 cases (incidence, 1/783; Fig. 1). One of these had an additional finding of maternal heterodisomic uniparental disomy of chromosome 17; no other cases had additional findings detectable by the SNP-based array, including other copy number variants $(\mathrm{CNVs})$ (resolution of $>0.5 \mathrm{Mb}$; Table 1 ). Of the 12 'normal' cases that presented with the 22q11.2 deletion, three cases (two in the set of twins) had $0.72 \mathrm{Mb}$ deletions; the remaining nine cases had the common 2.4-3.5 Mb deletion (Table 1, Fig. 2). Each case is schematically represented against the hg18 browser ideogram for chromosome 22 . The common A, B, C, and D low-copy repeats (LCRs) for the 22q11.2 deletion are shown. There is one small region $(190 \mathrm{~Kb})$ between LCR-B and LCR-C that is common to all 15 cases (Fig. 2). The only gene in this region is SCARF2.

Eighty percent $(12 / 15)$ of the 22q11.2 deletions identified were present on the maternally inherited chromosome (Table 1). Because mothers were not consented for analysis of their samples outside the scope of fetal results, it is unknown how many deletions on the maternal chromosome were de novo versus inherited deletions. Furthermore, the status of deletion on the paternal chromosome (cases 13,14 and 15) cannot be determined because paternal samples were not analyzed.

There was no significant difference in mean maternal age (32.6 years; range, $19.0-41.3$ years; standard deviation [SD], 5.9) for the 15 cases with the deletion compared with the entire analysis cohort (35.0 year; range, 15.0-52.0 year; SD, 5.3) ( $p=0.38)$.

Gestational age information, which was available for 10 of the 15 POC specimens with the 22q11.2 deletion, ranged from 6.4 to 13.6 weeks. Among those, 80\% (8/10) of the miscarriages occurred in the first trimester and the remainder occurred early in the second trimester. However, because gestational age at loss was available for less than $20 \%$ of the study cohort in total, no inference could be drawn about the relationship between gestational age and presence of the 22q11.2 deletion.

\section{Discussion}

Although gross chromosomal imbalances have been shown to be present in approximately two-thirds of all first trimester miscarriages $[9,16]$, relatively little information on the frequency of the 22q11.2 deletion in miscarriage is available. To gain insight into this question, we reviewed a large dataset of microarray results from 
Table 1 Description of cases with a 22q11.2 deletion

\begin{tabular}{|c|c|c|c|c|c|}
\hline Case no. & Category $^{a}$ & $\begin{array}{l}\text { NCBI36/hg18 Genomic Coordinates } \\
\text { (GRCh38/hg38 Genomic Coordinates) }\end{array}$ & Deletion size (Mb) & Parental origin & Additional findings \\
\hline 1 & Abnormal & $\begin{array}{l}16,930,000-20,430,000 \\
(18,067,234-21,745,711)\end{array}$ & 3.5 & Maternal & $X X Y$ \\
\hline 2 & Abnormal & $\begin{array}{l}18,630,000-20,130,00) \\
(20,262,477-21,445,711)\end{array}$ & 1.5 & Maternal & Trisomy 15 \\
\hline 3 & Abnormal & $\begin{array}{l}19,100,000-19,750,000 \\
(20,415,710-21,065,711)\end{array}$ & 0.65 & Maternal & Trisomy 16 \\
\hline 4 & Normal & $\begin{array}{l}17,400,000-19,780,000 \\
(19,032,487-21,095,711)\end{array}$ & 2.4 & Maternal & Maternal UPD17 \\
\hline 5 & Normal & $\begin{array}{l}16,980,000-20,500,000 \\
(18,117,233-21,815,711)\end{array}$ & 3.5 & Maternal & None \\
\hline 6 & Normal & $\begin{array}{l}16,940,000-20,250,000 \\
(18,077,234-21,565,711)\end{array}$ & 3.3 & Maternal & None \\
\hline 7 & Normal & $\begin{array}{l}17,140,000-19,940,000 \\
(18,772,487-21,255,711)\end{array}$ & 2.8 & Maternal & None \\
\hline 8 & Normal & $\begin{array}{l}17,280,000-19,790,000 \\
(18,912,487-21,105,711)\end{array}$ & 2.5 & Maternal & None \\
\hline 9 & Normal & $\begin{array}{l}17,280,000-19,700,000 \\
(18,912,487-21,015,711)\end{array}$ & 2.4 & Maternal & None \\
\hline $10^{\mathrm{b}}$ & Normal & $\begin{array}{l}19,070,000-19,790,000 \\
(20,385,710-21,105,711)\end{array}$ & 0.72 & Maternal & None \\
\hline $11^{b}$ & Normal & $\begin{array}{l}19,070,000-19,790,000 \\
(20,385,710-21,105,711)\end{array}$ & 0.72 & Maternal & None \\
\hline 12 & Normal & $\begin{array}{l}19,070,000-19,780,000 \\
(20,385,710-21,095,711)\end{array}$ & 0.71 & Maternal & None \\
\hline 13 & Normal & $\begin{array}{l}16,940,000-20,130,000 \\
(18,077,234-21,445,711)\end{array}$ & 3.2 & Paternal & None \\
\hline 14 & Normal & $\begin{array}{l}17,010,000-20,250,000 \\
(18,147,233-21,565,711)\end{array}$ & 3.2 & Paternal & None \\
\hline 15 & Normal & $\begin{array}{l}16,890,000-19,290,000 \\
(18,027,234-20,605,713)\end{array}$ & 2.4 & Paternal & None \\
\hline
\end{tabular}

${ }^{a}$ Based on the presence or absence of chromosome abnormalities that were detectable at the resolution of traditional karyotyping (i.e., $\geq 10 \mathrm{Mb}$ )

${ }^{\mathrm{b}}$ Non-identical twin gestation

POC specimens for the presence of 22q11.2 deletions. Among 22,451 miscarriage samples with fetal results, we observed the 22q11.2 deletion at an overall incidence of $1 / 1497$, which is significantly more frequent than the reported population prevalence of $1 / 4000-1 / 6000[4,5]$. Possible explanations for this discrepancy include the published general population prevalence potentially being an underestimate, and/or that some affected fetuses have major anomalies that lead to fetal demise $[17,18]$. For example, it is known, that cardiac defects are the primary cause [87\%] of mortality in infants with the deletion [1]. Consistent with this, other recent studies have found a higher frequency of the 22q11.2 deletion in prenatal cohorts and stillbirths (1/233 to $1 / 946)$ $[6-8,13,19]$.

The high variability of phenotypic presentation of the 22q11.2 deletion is well known, but it is not fully understood why some individuals with the 22q11.2 deletion are more severely affected than others [20, 21]. Recent evidence suggests a role for additional genetic variants that modify risk for congenital heart defects in some patients with the deletion [22]. Conversely, other studies have found no evidence of an increase in novel genomewide CNVs in patients with the 22q11.2 deletion [23]. However, there is still the potential for other undetectable mutations and /or environmental factors to impact the severity of cases with the 22q11.2 deletion as was proposed to modify clinical severity of the 16p21.2 deletion and termed a 'two-hit hypothesis' [24].

In this study, we found the incidence of 22q11.2 deletions in samples with additional abnormalities was significantly lower than its incidence in samples without them (incidence, $1 / 4351$ vs. $1 / 783 ; p<0.01$ ). A previous study comprising a subset of this study's cohort (the first 2392 samples of 26,101 total) found that the distribution of all subchromosomal CNVs, including the 22q11.2 deletion, was similarly skewed, with a higher proportion of variants present in cytogenetically normal samples [9]. The authors of that study suggested that the higher incidence of copy-number changes in cytogenetically 


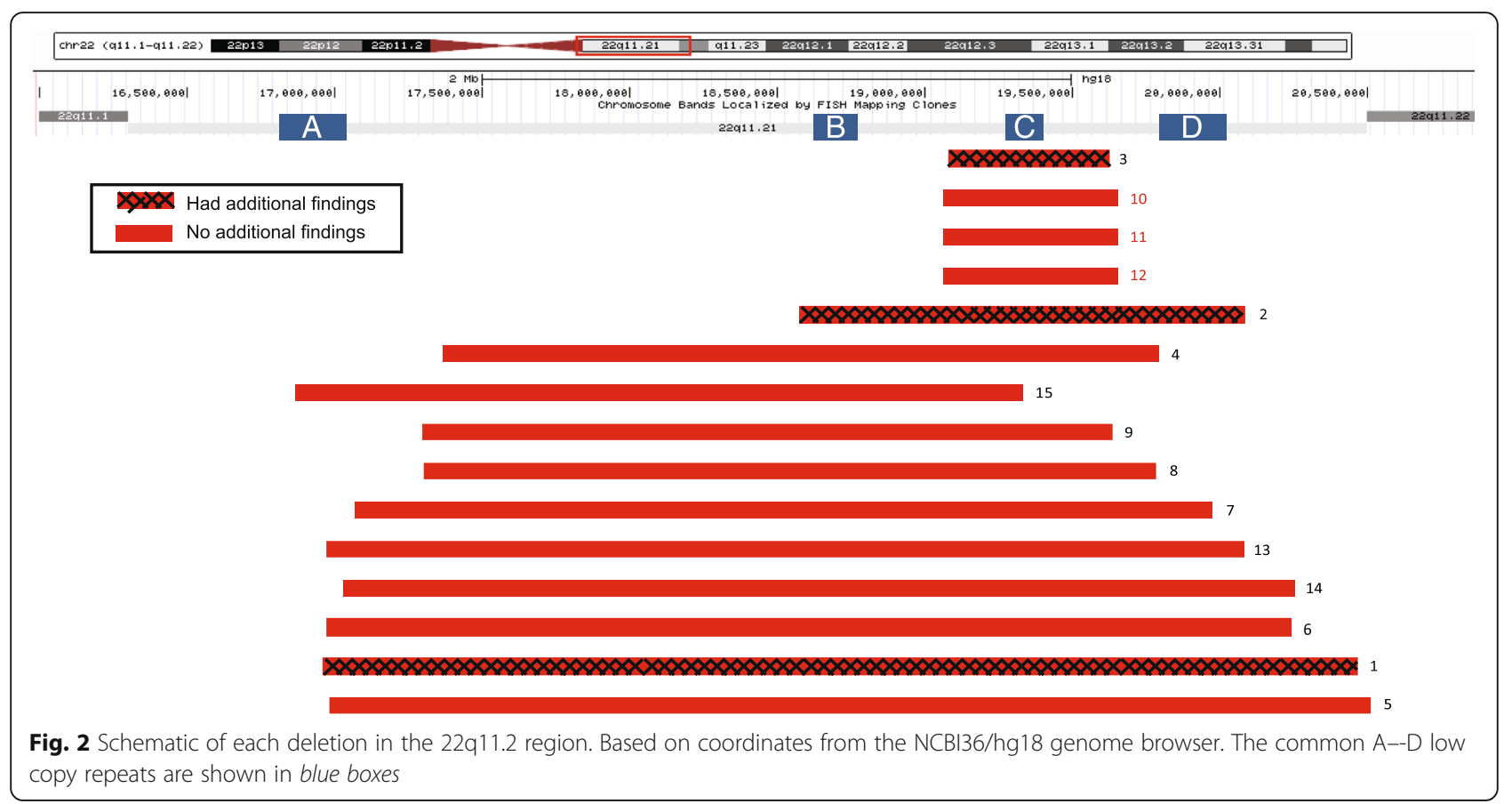

normal samples suggested that these findings "likely contributed to miscarriage causality" [9]. That study also found that the frequency of concurrent double aneuploidies in miscarriage cohorts was lower than was expected based on the reported incidence of each individual anomaly [9]. Presumably more than one significant genetic abnormality leads to selective pressure against implantation, or against continuation of pregnancies beyond 6 weeks. Likewise, if the 22q11.2 deletion were an independent cause of miscarriage, it would likely be observed less frequently in cases with additional chromosomal anomalies.

The combination of the 22q11.2 deletion's high phenotypic variability, high frequency in stillbirth and prenatal samples and high incidence found in this study suggests that the published general population incidence may be an underestimate and/or that the 22q11.2 deletion could be a causal factor for miscarriage.

Other findings of this study were consistent with previous studies. First, the majority (67\%) of 22q11.2 deletions identified in this study had the common LCRA to LCR-D, 2.0-3.5 Mb-sized, deletion [1]; the remaining deletions ranged in size from 0.65 to $1.5 \mathrm{Mb}$. Second, $80 \%(12 / 15)$ of $22 \mathrm{q} 11.2$ deletions in this study were on the maternally inherited chromosome, similar to previous studies that found a higher proportion of 22 q11.2 deletions on the maternal chromosome (76\% in prenatally diagnosed cases and $60 \%$ in postnatal cases) $[17,23]$. Although the exact reason for this skew toward maternal origin is unknown, several factors have been considered, including an increased rate of recombination in this region in female germ cells, a mediating role of the Y chromosome due to homology with the 22q11.2 region, reduced fitness for males with the deletion, and a skewed inheritance pattern in male vs. female offspring [23-25].

Interestingly, a region containing one known gene, $S C A R F 2$, was common to all fifteen 22q11.2 deletion cases. Mutations in SCARF2 are associated with Van Den Ende-Gupta syndrome, an autosomal recessive condition characterized by craniofacial and skeletal malformations [26]. SCARF2 is thought to play a role in cell signaling pathways but it is not well characterized. It may play an important role the development of various organ systems [26].

Approximately $7 \%$ of individuals who have a child with a 22q11.2 deletion also have the deletion [1]. Therefore, identification of a 22q11.2 deletion in a miscarriage specimen should prompt evaluation of the parent(s) to determine whether there are clinical and reproductive risks for the parents. Additional medical screening and care is recommended for all individuals with the $22 \mathrm{q} 11.2$ deletion, including adults diagnosed later in life [27, 28]. For adults with the deletion, the recurrence risk for each subsequent pregnancy is $50 \%$. Parents with an affected child, but who do not have the deletion themselves, may have a slightly elevated $(\sim 1 \%)$ recurrence risk in each pregnancy, likely due to gonadal mosaicism [1]. Thus, knowing if a POC specimen has the 22q11.2 deletion can lead to better recurrence risk counseling and future pregnancy management for families. 
The results of this study show a higher $22 \mathrm{q} 11.2$ deletion incidence in the miscarriage population than literature reports of the live-born population. This implies that either the population prevalence of the 22q11.2 deletion in the live-born population has been underestimated or that the $22 \mathrm{q} 11.2$ deletion is a causative factor in miscarriage. Further studies are needed to determine the true incidence of the 22q11.2 deletion syndrome in the live-born and prenatal population. Additionally, the advantages of chromosomal microarray analysis support its use as a first-line test for the analysis of POC samples.

\section{Methods}

A retrospective review of 26,101 consecutive fresh POC specimens received by a single Clinical Laboratory Improvement Act (CLIA)-certified, College of American Pathologists (CAP)-accredited laboratory for clinical miscarriage testing over a 6-year period (April 2010May 2016) was performed to determine the incidence of the 22q11.2 deletion. A maternal blood sample was requested with each specimen. For each patient, information about maternal age, gestational age, egg donor use, and indication for testing was requested, and all samples were de-identified before review. Additional clinical information including previous pregnancy history, method of conception, pregnancy records and family history was not collected by the laboratory. This study was granted a waiver of the requirement for documentation of informed consent by the institutional review board (E\&I ID\# 15148-01).

Data on all clinical findings were previously published for the first 2392 cases of this data set, which included one case with the 22q11.2 deletion [9]. Additionally, all syndromic CNVs in karyotypically normal samples from 17,424 cases in this data set were presented at the American Society of Reproductive Medicine 2016 meeting. This included 6 cases with the 22q11.2 deletion [29].

Upon receipt at the commercial reference laboratory, POC specimens were processed by separating chorionic villi from maternal decidua using a standardized technique [30]. These, along with the maternal samples, were genotyped using lllumina CytoSNP-12b microarrays, which measures approximately 300,000 SNPs across the genome (roughly one every $10 \mathrm{~kb}$ ) according to the manufacturer's instructions (Illumina, Inc., San Diego, CA). After a genomic sample is run on a SNP array the results must pass an in-house quality control test before further analysis is done. Genotyped samples were analyzed for DNA copy number, uniparental disomy (UPD), parental origin of chromosome abnormalities, and maternal cell contamination (MCC) using the previously described proprietary Parental Support ${ }^{\mathrm{TM}}$ algorithm [31]. In short, the allele ratios are calculated for each locus across a chromosome, and the clustering of allele ratios is indicative of the copy number for that chromosome. Comparison of the SNP identities between the maternal and POC data is used to identify maternal cell contamination, the parental origin of aneuploidy and unbalanced chromosome segments. Since parents were not consented for testing of their DNA nor is the father genetic material tested, we are not able to determine whether 22q11.2 deletions are inherited or de novo. Samples were classified as 'abnormal' or 'normal' based on the presence or absence of chromosome abnormalities that could be detected at the resolution of traditional karyotyping (i.e., $>10 \mathrm{Mb}$ ). Coordinates for copy number variants $(\mathrm{CNVs})>0.5 \mathrm{Mb}$ were entered into the NCBI36/hg18 genome browser to determine clinical significance based on genes affected and previously reported overlapping CNVs. These coordinates were then converted to the GRCh38/hg38 assembly coordinates using the Lift Genome Annotations tool. To determine the statistical significance of maternal age values and of the incidence of the 22q11.2 deletion, independent two-sample t-tests were performed.

\section{Abbreviations \\ CNVs: Copy number variants; LCR: Low-copy repeats; Mb: Millions of base pairs; MCC: Maternal cell contamination; POC: Products of conception; SNP: Single-nucleotide polymorphism; UPD: Uniparental disomy}

\section{Acknowledgements}

We thank Dr. Peter Benn, DSc for his helpful discussions while writing this manuscript

\section{Funding}

Not applicable.

\section{Availability of data and materials}

The raw data and materials for this study have been de-identified. This data is held by Natera and is freely available to researchers who follow the appropriate procedures.

\section{Authors' contributions}

MKM: Made substantial contributions to conception and design of the study and performed primary data analysis/interpretation of data; drafted the manuscript and revised it for important intellectual content; and gives final approval of this version. KM: Made substantial contributions to conception and design of the study and performed interpretation of data; revised the manuscript critically for important intellectual content, and gives final approval of this version. BP: Made substantial contributions to conception and design of the study and performed interpretation of data; revised the manuscript for important intellectual content; and gives final approval of this version. MY: Made substantial contributions to design of the study and acquired the data; revised the manuscript for important intellectual content, and gives final approval of this version. KP: Made substantial contributions to design of the study and acquired the data; revised the manuscript for important intellectual content, and gives final approval of this version. SI: Made substantial contributions to data analysis/interpretation of data; drafted the manuscript and revised it critically for important intellectual content; and gives final approval of this version. SK: Made substantial contributions to data analysis/interpretation of data; participated in drafting of the manuscript and its subsequent revision for important intellectual content; and gives final approval of this version. SS: Made substantial contributions to conception and design of the study and performed interpretation of data; revised the manuscript for important intellectual content, and gives final approval of this version. ZPD: Made substantial contributions to conception and design of 
the study and performed interpretation of data; revised the manuscript critically for important intellectual content, and gives final approval of this version. KAM: Made substantial contributions to conception and design of the study and performed interpretation of data; revised the manuscript critically for important intellectual content, and gives final approval of this version.

\section{Competing interests}

All authors except KP are employees of Natera and own stock/options to purchase stock from the company. KP is a former employee of Natera and owns Natera stock

\section{Consent for publication}

Not applicable since this manuscript did not contain any individual's personal data in any form.

\section{Ethics approval and consent to participate}

This study was granted a waiver of the requirement for documentation of informed consent by the institutional review board (E\&I ID\# 15148-01).

Received: 8 November 2016 Accepted: 22 February 2017

Published online: 09 March 2017

\section{References}

1. McDonald-McGinn DM, Sullivan KE, Marino B, Philip N, Swillen A, Vorstman JA, Zackai EH, Emanuel BS, Vermeesch JR, Morrow BE, et al. 22q11.2 deletion syndrome. Nat Rev Dis Primers. 2015;1:15071.

2. McDonald-McGinn DM, Emanuel BS, Zackai EH. 22q11.2 Deletion Syndrome 1999 Sep 23 [Updated 2013Feb 28]. In: Pagon RA, Adam MP, Ardinger HH, et al., editors. GeneReviews ${ }^{\circledast}$ [Internet]. Seattle: University of Washington, Seattle; 1993-2017.

3. Edelmann L, Pandita RK, Morrow BE. Low-copy repeats mediate the common 3-Mb deletion in patients with velo-cardio-facial syndrome. Am J Hum Genet. 1999;64:1076-86

4. Botto LD, May K, Fernhoff PM, Correa A, Coleman K, Rasmussen SA, Merritt RK, O'Leary LA, Wong LY, Elixson EM, et al. A population-based study of the 22q11.2 deletion: phenotype, incidence, and contribution to major birth defects in the population. Pediatrics. 2003;112:101-7.

5. Oskarsdottir S, Vujic M, Fasth A. Incidence and prevalence of the 22 q11 deletion syndrome: a population-based study in Western Sweden. Arch Dis Child. 2004:89:148-51.

6. Gross SJ, Stosic M, McDonald-McGinn DM, Bassett AS, Norvez A, Dhamankar R, Kobara K, Kirkizlar E, Zimmermann B, Wayham N, et al. Clinical experience with single-nucleotide polymorphism-based non-invasive prenatal screening for 22q11.2 deletion syndrome. Ultrasound Obstet Gynecol. 2016;47:177-83.

7. Grati FR, Molina Gomes D, Ferreira JC, Dupont C, Alesi V, Gouas L, HorelliKuitunen N, Choy KW, Garcia-Herrero S, de la Vega AG, et al. Prevalence of recurrent pathogenic microdeletions and microduplications in over 9500 pregnancies. Prenat Diagn. 2015;35:801-9.

8. Wapner RJ, Martin CL, Levy B, Ballif BC, Eng CM, Zachary JM, Savage M, Platt LD, Saltzman D, Grobman WA, et al. Chromosomal microarray versus karyotyping for prenatal diagnosis. N Engl J Med. 2012;367:2175-84.

9. Levy B, Sigurjonsson S, Pettersen B, Maisenbacher MK, Hall MP, Demko Z, Lathi RB, Tao R, Aggarwal V, Rabinowitz M. Genomic imbalance in products of conception: single-nucleotide polymorphism chromosomal microarray analysis. Obstet Gynecol. 2014;124:202-9.

10. Hillman SC, Pretlove S, Coomarasamy A, McMullan DJ, Davison EV, Maher ER, Kilby MD. Additional information from array comparative genomic hybridization technology over conventional karyotyping in prenatal diagnosis: a systematic review and meta-analysis. Ultrasound Obstet Gynecol. 2011:37:6-14.

11. Shimokawa O, Harada N, Miyake N, Satoh K, Mizuguchi T, Niikawa N, Matsumoto N. Array comparative genomic hybridization analysis in first-trimester spontaneous abortions with 'normal' karyotypes. Am J Med Genet A. 2006;140:1931-5.

12. Miller DT, Adam MP, Aradhya S, Biesecker LG, Brothman AR, Carter NP, Church DM, Crolla JA, Eichler EE, Epstein CJ, et al. Consensus statement: chromosomal microarray is a first-tier clinical diagnostic test for individuals with developmental disabilities or congenital anomalies. Am J Hum Genet. 2010;86:749-64.

13. Shaffer LG, Dabell MP, Fisher AJ, Coppinger J, Bandholz AM, Ellison JW, Ravnan JB, Torchia BS, Ballif BC, Rosenfeld JA. Experience with microarray- based comparative genomic hybridization for prenatal diagnosis in over 5000 pregnancies. Prenat Diagn. 2012:32:976-85.

14. Fiorentino F, Napoletano S, Caiazzo F, Sessa M, Bono S, Spizzichino L, Gordon A, Nuccitelli A, Rizzo G, Baldi M. Chromosomal microarray analysis as a first-line test in pregnancies with a priori low risk for the detection of submicroscopic chromosomal abnormalities. Eur J Hum Genet. 2013;21:725-30

15. Warren JE, Turok DK, Maxwell TM, Brothman AR, Silver RM. Array comparative genomic hybridization for genetic evaluation of fetal loss between 10 and 20 weeks of gestation. Obstet Gynecol. 2009;114:1093-102.

16. Menasha J, Levy B, Hirschhorn K, Kardon NB. Incidence and spectrum of chromosome abnormalities in spontaneous abortions: new insights from a 12-year study. Genet Med. 2005;7:251-63.

17. Besseau-Ayasse J, Violle-Poirsier C, Bazin A, Gruchy N, Moncla A, Girard F, Till M, Mugneret F, Coussement A, Pelluard F, et al. A French collaborative survey of 272 fetuses with 22q11.2 deletion: ultrasound findings, fetal autopsies and pregnancy outcomes. Prenat Diagn. 2014;34:424-30.

18. Wertaschnigg D, Jaeggi M, Chitayat D, Shannon P, Ryan G, Thompson M, Yoo SJ, Jaeggi E. Prenatal diagnosis and outcome of absent pulmonary valve syndrome: contemporary single-center experience and review of the literature. Ultrasound Obstet Gynecol. 2013;41:162-7.

19. Reddy UM, Page GP, Saade GR, Silver RM, Thorsten VR, Parker CB, Pinar H, Willinger M, Stoll BJ, Heim-Hall J, et al. Karyotype versus microarray testing for genetic abnormalities after stillbirth. N Engl J Med. 2012;367:2185-93.

20. McDonald-McGinn DM, Tonnesen MK, Laufer-Cahana A, Finucane B, Driscoll DA, Emanuel BS, Zackai EH. Phenotype of the 22q11.2 deletion in individuals identified through an affected relative: cast a wide FISHing net! Genet Med. 2001:3:23-9.

21. Digilio MC, Angioni A, De Santis M, Lombardo A, Giannotti A, Dallapiccola B, Marino B. Spectrum of clinical variability in familial deletion 22q11.2: from full manifestation to extremely mild clinical anomalies. Clin Genet. 2003;63:308-13.

22. Mlynarski EE, Xie M, Taylor D, Sheridan MB, Guo T, Racedo SE, McDonaldMcGinn DM, Chow EW, Vorstman J, Swillen A, et al. Rare copy number variants and congenital heart defects in the 22q11.2 deletion syndrome. Hum Genet. 2016:135:273-85.

23. Delio M, Guo T, McDonald-McGinn DM, Zackai E, Herman S, Kaminetzky M, Higgins AM, Coleman K, Chow C, Jalbrzikowski M, et al. Enhanced maternal origin of the 22q11.2 deletion in velocardiofacial and DiGeorge syndromes. Am J Hum Genet. 2013:92:439-47.

24. Torres-Juan L, Rosell J, Sanchez-de-la-Torre M, Fibla J, Heine-Suner D. Analysis of meiotic recombination in 22q11.2, a region that frequently undergoes deletions and duplications. BMC Med Genet. 2007;8:14.

25. Costain G, Chow EW, Silversides CK, Bassett AS. Sex differences in reproductive fitness contribute to preferential maternal transmission of 22q11.2 deletions. J Med Genet. 2011;48:819-24.

26. Anastasio N, Ben-Omran T, Teebi A, Ha KC, Lalonde E, Ali R, Almureikhi M, Der Kaloustian VM, Liu J, Rosenblatt DS, et al. Mutations in SCARF2 are responsible for Van Den Ende-Gupta syndrome. Am J Hum Genet. 2010:87:553-9.

27. Fung WL, Butcher NJ, Costain G, Andrade DM, Boot E, Chow EW, Chung B, Cytrynbaum C, Faghfoury $H$, Fishman L, et al. Practical guidelines for managing adults with 22q11.2 deletion syndrome. Genet Med. 2015;17(8): 599-609.

28. McDonald-McGinn DM, Zackai EH. Genetic counseling for the 22q11.2 deletion. Dev Disabil Res Rev. 2008;14:69-74.

29. Maisenbacher MK, Merrion K, Sigurjonsson S, Paik K, Young M, Dodd M, Pettersen B. A crossroads: non-invasive prenatal screening (NIPT) microdeletion syndromes identified in products of conception (POC) samples. Baltimore: American Society of Reproductive Medicine; 2015.

30. Lathi RB, Milki AA. Tissue sampling technique affects accuracy of karyotype from missed abortions. J Assist Reprod Genet. 2002;19:536-8.

31. Johnson DS, Gemelos G, Baner J, Ryan A, Cinnioglu C, Banjevic M, Ross R, Alper M, Barrett B, Frederick J, et al. Preclinical validation of a microarray method for full molecular karyotyping of blastomeres in a 24-h protocol. Hum Reprod. 2010;25:1066-75. 